\title{
Biomimetic Surface Modifications Based On The Cyanobacterial Iron Chelator Anachelin
}

Stefan Zürcher, * David Wäckerlin, Yann Bethuel, Barbora Malisova, Marcus Textor, Samuele Tosatti, and Karl Gademann, *.

Laboratory for Surface Science and Technology, Department of Materials,

Surface Solutions GmbH, and

Laboratorium für Organische Chemie, Department of Chemistry and Applied Biosciences, ETH Zürich, Wolfgang-Pauli-Str. 10, CH-8093 Zürich, Switzerland

gademann@org.chem.ethz.ch

\section{Supporting Information}

Table of contents

1. Synthesis of compound 2

2. Synthesis of compound 3 


\section{Synthesis of compound 2}<smiles></smiles>

SC1<smiles>CCOCC(C)(C)OCC(=O)NC1Cc2cc(O)c(O)cc2[N+](C)(C)C1</smiles>

2

SC1 (Prepared according to $\left.{ }^{1}\right)(6.8 \mathrm{mg}, 22 \mathrm{umol})$ was dissolved at $0{ }^{\circ} \mathrm{C}$ (ice-bath) in $\mathrm{HCl}(4 \mathrm{M})$ in dioxane $(0.5 \mathrm{ml})$. The reaction mixture was stirred for $1.5 \mathrm{~h}$ at $0{ }^{\circ} \mathrm{C}$, whereas after 30 minutes a yelloworange precipitate formed, and for 10 minutes at RT under Ar. The solvent was removed under reduced pressure and the resulting off-white powder was dried under high vacuum. The residue was suspended in DMF (1 ml) and $\mathrm{CH}_{2} \mathrm{Cl}_{2}(1 \mathrm{ml})$ and $\mathrm{N}$-methylmorpholine (50 ul) was added. Additional DMF (1 ml) was added and the reaction mixture was stirred for 15 minutes until an orange-yellow solution resulted. mPEGASA (50 mg, ca. 10 umol) was added in one portion and the orange-yellow solution was stirred at RT under Ar under the exclusion of light for $18 \mathrm{~h}$. The reaction mixture was then filtered, and diluted with 50 $\mathrm{ml}$ diethylether. The solution was allowed to stand for 30 minutes at $4{ }^{\circ} \mathrm{C}$, after which a white precipitate formed. The precipitate was filtered and washed extensively with diethylether. The product was dried under high vacuum to give 2 (33.2 $\mathrm{mg}$, ca $6.6 \mathrm{umol}, 66 \%$ ) orange solid.

\section{Synthesis of compound 3}

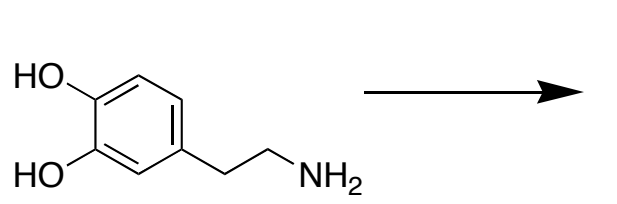

Dopamine<smiles>CC(C)CC(C)(CO)COCC(=O)NCCc1ccc(O)c(O)c1</smiles>

3

Dopamine hydrochloride $(50 \mathrm{mg}, 0.26 \mathrm{mmol})$ and $\mathrm{N}$-methylmorpholine $(50 \mu \mathrm{L})$ were dissolved in Ethanol $(20 \mathrm{~mL})$. mPEG-ASA $(1.34 \mathrm{~g}$, ca. $0.26 \mathrm{mmol})$ dissolved in $5 \mathrm{~mL}$ chloroform was added and the mixture was stirred at room temperature for 2.5 hours. The crude reaction mixture was evaporated to about $15 \mathrm{~mL}$ on a rotary evaporaor and diethylether $(40 \mathrm{~mL})$ was added. The solution was allowed to stand for 30 minutes at $4{ }^{\circ} \mathrm{C}$, and then at $-20{ }^{\circ} \mathrm{C}$ over night, after which a white precipitate formed. The precipitate was filtered and washed extensively with diethylether. The product was dried under high vacuum to give $\mathbf{3}$ (1.26 $\mathrm{g}$, ca $0.24 \mathrm{mmol}, 92 \%$ ) as a white solid. 


\section{Synthesis of compound 4}<smiles></smiles>

Mimosine<smiles>CCOCC(C)OCC(=O)NC([O-])C[n+]1ccc(O)c(O)c1</smiles>

4

Mimosine (10 mg, $0.05 \mathrm{mmol})$ was dissolved in sodiumborate buffer (5 mL, $50 \mathrm{mM}, \mathrm{pH} 8.4)$. mPEGASA (252 mg, ca. $0.05 \mathrm{mmol}$ ) was added and the resulting mixture was stirred at room temperature for 16 hours after which time a $\mathrm{HCl}(0.5 \mathrm{~mL}, 2 \mathrm{~N})$ solution was added. The compound was extracted into chloroform and the combined organic phases were dried with $\mathrm{MgSO}_{4}$. After reducing the solvent to $5 \mathrm{~mL}$ on a rotary evaporaor, diethylether $(40 \mathrm{~mL})$ was added. The solution was allowed to stand for 30 minutes at $4{ }^{\circ} \mathrm{C}$, and then at $-20{ }^{\circ} \mathrm{C}$ over night, after which a white precipitate formed. The precipitate was filtered and washed extensively with diethylether. The product was dried under high vacuum to give 4 (220 mg, ca 0.04 mmol, $85 \%$ ) as a white solid.

\section{Synthesis of compound 5}

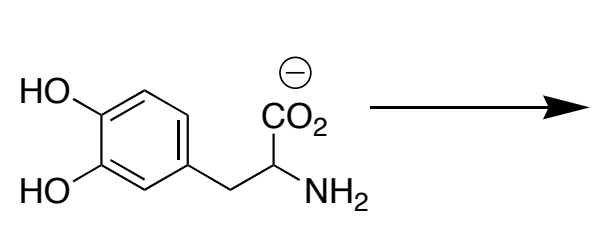

L-DOPA<smiles>CC1CCCCCC(COCC(=O)NC([O-])Cc2ccc(O)c(O)c2)C1</smiles>

5

L-DOPA (3.9 mg, $0.02 \mathrm{mmol}$ ) was dissolved in sodiumborate buffer (4 mL, $50 \mathrm{mM}, \mathrm{pH} 8.4$ ) under nitrogen. mPEG-ASA (100 mg, ca. $0.02 \mathrm{mmol}$ ) was added and the resulting mixture was stirred at room temperature for 24 hours after which time a $\mathrm{HCl}(0.5 \mathrm{~mL}, 2 \mathrm{~N})$ solution was added. The compound was extracted into chloroform and the combined organic phases were dried with $\mathrm{MgSO}_{4}$. After reducing the solvent to $5 \mathrm{~mL}$ on a rotary evaporaor, diethylether $(40 \mathrm{~mL})$ was added. The solution was allowed to stand for 30 minutes at $4{ }^{\circ} \mathrm{C}$, and then at $-20^{\circ} \mathrm{C}$ over night, after which a white precipitate formed. The precipitate was filtered and washed extensively with diethylether. The product was dried under high vacuum to give 5 (90 mg, ca $0.017 \mathrm{mmol}, 87 \%$ ) as a white solid. 


\section{X-ray Photoelectron Spectroscopy (XPS).}

XPS analyses were performed using a VG thetaprobe spectrophotometer equipped with a concentric hemispherical analyzer in the standard configurations. Spectra were acquired at a base pressure of $10^{-9}$ mbar or below using a monochromatic Al-K $\alpha$ source with a spot size of $300 \mu \mathrm{m}$. The CHA was used in the fixed-analyzer-transmission mode. Pass energies used for survey scans and detailed scans were 250 and $100 \mathrm{eV}$, respectively for titanium (Ti2p), carbon (C1s), oxygen (O1s), nitrogen (N1s) and silicon (Si2p). Acquisition times were approximately $5 \mathrm{~min}$ for survey scans and $30 \mathrm{~min}$ (total) for all elemental scans. These experimental conditions were chosen in order to have an adequate signal-to-noise ratio in a minimum time and to limit beam-induced damage. Under these conditions, sample damage was negligible, and reproducible analyzing conditions were obtained on all samples. The measurements were performed with a takeoff angle (detection angle to the surface) of $53^{\circ}$ with respect to the surface normal. All recorded spectra were referenced to the aliphatic hydrocarbon $\mathrm{C} 1 \mathrm{~s}$ signal at $285.0 \mathrm{eV}$. Data were analyzed using the program CasaXPS [Version 2.3.5 www.casaxps.com]. The signals were fitted using Gaussian-Lorentzian functions and least-squares-fit routines following Shirley iterative background subtraction. Sensitivity factors were calculated using published ionization cross sections ${ }^{2}$ corrected for the energy dependence of the attenuation length, and the angular asymmetry function ${ }^{3}$.

The four different molecules (mPEG-anacat 2, mPEG-dopamin 3, mPEG-mimosine 4 and mPEG-LDOPA 5) were adsorbed as described in the text on silicon wafers coated with $2.3 \mathrm{~nm}$ natural $\mathrm{SiO}_{2}$ and 6 nm sputtere coated $\mathrm{TiO}_{2}$. Due to the very thin $\mathrm{TiO}_{2}$ Layer, $\mathrm{SiO}_{2}$ and $\mathrm{Si}$ are still detectable with XPS. 
Normalized atomic concentrations

$\begin{array}{llllll} & \% \mathrm{C} & \% \mathrm{~N} & \% \mathrm{O} & \% \mathrm{Si} & \% \mathrm{Ti} \\ \mathbf{2} & & & & & \\ \mathbf{2} \text { as deposited } & 41.9 & 1.8 & 44.7 & 2.6 & 8.9 \\ \mathbf{2} \text { after H2 } & 31.6 & 2.2 & 50.9 & 2.2 & 13.1 \\ \mathbf{3} \text { as deposited } & 42.0 & 0.7 & 45.1 & 2.6 & 9.6 \\ \mathbf{3} \text { after H2 } & 19.1 & 0.8 & 57.9 & 5.5 & 16.7 \\ \mathbf{4} \text { as deposited } & 19.9 & 0.9 & 57.7 & 3.4 & 18.0 \\ \mathbf{4} \text { after H2 } & 16.9 & 0.9 & 59.4 & 2.7 & 20.0 \\ \mathbf{5} \text { as deposited } & 16.8 & 1.1 & 59.4 & 2.4 & 20.3 \\ \mathbf{5} \text { after H2 } & 17.3 & 0.8 & 59.8 & 3.5 & 18.6\end{array}$

Atomic percentage of the different carbon species found on the different surfaces before and after buffer immersion for 2 days.

$\begin{array}{lcccc} & \begin{array}{c}\text { C 1s } \\ \text { aliphatic }\end{array} & \begin{array}{c}\text { C 1s } \\ \text { PEG }\end{array} & \begin{array}{c}\text { C 1s } \\ \text { amide }\end{array} & \begin{array}{c}\text { C 1s } \\ \text { carboxy }\end{array} \\ \mathbf{2} \text { as deposited } & 69.0 & 16.9 & 7.7 & 6.4 \\ \mathbf{2} \text { after buffer } & 9.4 & 87.6 & 3.0 & 0.0 \\ \mathbf{3} \text { as deposited } & 14.7 & 76.9 & 8.4 & 0.0 \\ \mathbf{3} \text { after buffer } & 6.8 & 88.7 & 4.5 & 0.0 \\ \mathbf{4} \text { deposited } & 25.6 & 67.3 & 7.2 & 0.0 \\ \mathbf{4} \text { after buffer } & 47.4 & 41.8 & 10.8 & 0.0 \\ \mathbf{5} \text { deposited } & 65.3 & 23.4 & 11.3 & 0.0 \\ \mathbf{5} \text { after buffer } & 62.9 & 25.1 & 5.4 & 6.6 \\ \end{array}$


Figure 1. XPS Carbon 1s Peaks for the four adsorbed molecules before and after buffer Immersion for 2 days

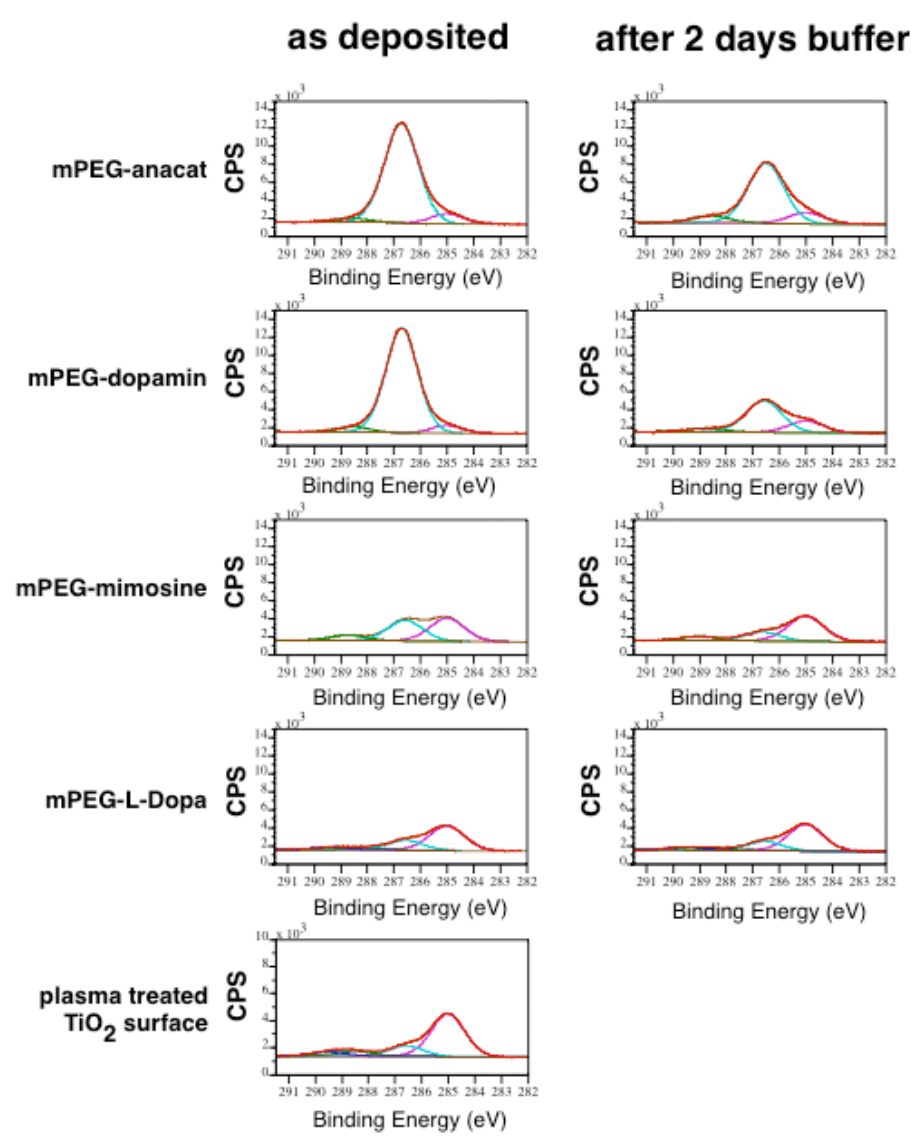

\section{References}

(1) Gademann, K. ChemBioChem 2005, 6, 913-919.

(2) Scofield, J. H. Journal Of Electron Spectroscopy And Related Phenomena 1976, 8, 129-137.

(3) Reilman, R. F.; Msezane, A.; Manson, S. T. Journal Of Electron Spectroscopy And Related Phenomena 1976, 8, 389-394. 